\title{
Alex C. Michalos: Pioneer of Quality of Life and Social Indicators Research
}

\author{
Bruno D. Zumbo
}

Published online: 19 December 2013

(C) Springer Science+Business Media Dordrecht and The International Society for Quality-of-Life Studies (ISQOLS) 2013

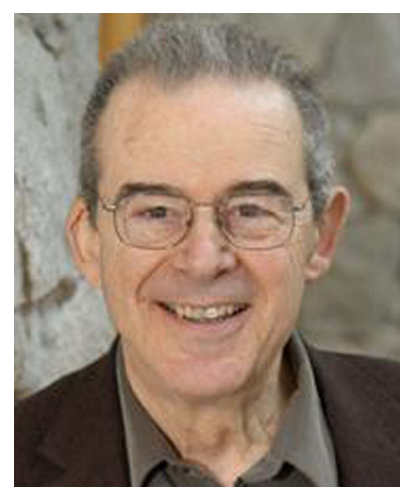

When I think of pioneers I imagine a hardy people traveling from a former life to a new unsettled place full of unknowns. My image of pioneers is influenced by John Wayne movies and the TV show Bonanza. These pioneers are, of course, not starting from nothing because they bring with them their tools, ideas, and beliefs from their earlier lives. I imagine life as a pioneer to be risky, exhausting, and chalk full of prospecting.

These images capture some of the main features of what I imagine to be my friend and longtime research collaborator Alex C. Michalos' pioneering life in quality life and social indicators research. He traveled from the comforts of a well-established and highly successful life well known for his work in philosophy of science, logic, and ethics to break new ground in social indicators and quality of life research. He brought with him his tools of theorizing and formalism as well as a love for data, surveys, evaluation and decision making, data analysis and a deep foundation in philosophical Pragmatism that can be evidenced in all of his work.

B. D. Zumbo $(\bowtie)$

Department of ECPS, The University of British Columbia, Scarfe Building, 2125 Main Mall, Vancouver,

BC, Canada V6T 1Z4

e-mail: bruno.zumbo@ubc.ca 
Although I will focus on Alex's work in quality of life and social indicators, his influence continues to be felt in academic philosophy where he is well known as the founder and Editor in Chief of the oft-cited Journal of Business Ethics. When I first met Alex, I knew him as a philosopher having read his Principles of Logic (1969), and The Popper-Carnap Controversy (1970). His reviews in philosophical journals were always incisive and very interesting to read, and a gold mine for graduate students interested in broad perspective on philosophical problems.

Alex is currently Emeritus Professor in Political Science at the University of Northern British Columbia, where he taught from 1994 to 2001 and served as Chancellor from 2007 to 2010. He was Professor of Philosophy at University of Guelph from 1966 to 1994, and Assistant Professor at State University of New York (1964-1966) and at State College, St. Cloud (1962-1964). Alex earned his Ph.D. in Philosophy of Science (1965), B.D. in history of religions and M.A. in logic (1961) all from the University of Chicago, and his B.A. from Western Reserve University (1957).

One can imagine how precarious it feels to try and capture such a productive and influential scholarly life as Alex's in a limited number of words so I will relieve myself of any such aspirations and give you what I believe are his most impactful contributions to quality of life and social indicators research and make him an unprecedented pioneer in the field.

1. His creation and ongoing editorship of the journal Social Indicators Research. Alex, and a small band of fellow pioneers, founded the journal in 1974. Alex has remained at the helm of the journal through its 114 volumes and 3149 articles published to date. The journal is important in the history of the discipline because it gave scholars an identity as well a place to publish (and read) work in the field. The journal, like Alex himself, takes a broad view of the field and includes empirical, philosophical and methodological studies.

2. His 1985 paper introducing, describing, and empirically testing Multiple Discrepancies Theory (MDT) is developed with an eye to conceptual detail and is an exemplar of solid theory building and testing. In the paper, Alex clearly states six basic hypotheses, extensive supporting evidence, and how the basic hypotheses yield five derived hypotheses that lend themselves to empirical test. The clarity and rigorous account, including the historical antecedents, is what makes the paper a required reading, and a lovely exemplar of how a seasoned philosopher of science builds and empirically tests theories in the social sciences.

3. His comprehensive 1991 four-volume Global Report on Student Well-being. The data are rich and the analyses are detailed.

4. His embracing of a life well lived that includes scholarship that impacts the community. There are many examples of this but my personal favorite is our joint creation of the University of Northern British Columbia Institute for Social Research and Evaluation. The institute is a partnership with the community to gain greater understanding of the social issues of central British Columbia.

5. His work with emerging scholars locally, nationally and internationally. Alex is well-known for his support of emerging scholars by way of working with them to publish their papers and encouraging them to contribute to conferences and associations. 
6. His tireless work as the Editor of the soon to be published 12 Volume Encyclopedia of Quality of Life and Well-Being Research. At last count, there will be 2053 entries ranging in length from a few hundred words to several thousand words per entry. This monumental task is the first comprehensive multi disciplinary reference work on scientific and other scholarly research in the social, behavioral and health sciences on quality of life and well-being. The encyclopedia alone is sufficient for pioneer status.

7. It is breath-taking to imagine how one person could have done so much, and so well. He has published 26 books and over 115 refereed articles and founded or cofounded seven scholarly journals. In addition, he is general editor and founder of the Social Indicators Research Book Series (having published 52 volumes). He has served as president of the Canadian Commission for UNESCO's Sectoral Commission on Natural, Social and Human Sciences (2004-2008), Academy II (Humanities and Social Sciences) of the Royal Society of Canada (2000-2002), Society for Philosophy and Technology (1983-1985) and the International Society for Quality of Life Studies (1998-2000), and has served as director of research for the Canadian Index of Wellbeing (2006-2011).

8. Not surprisingly, given his tremendous career, he has won several awards of distinction, including most notably the Gold Medal for Achievement in Research (2004) from the Social Sciences and Humanities Research Council of Canada (the Council's highest honor), Member of the Order of Canada, C.M. (2010), Queen Elizabeth II Diamond Jubilee Medal (2012), Award for the Betterment of the Human Condition (2003) from the International Society for Quality of Life Studies (ISQOLS), the ISQOLS Award for Extraordinary Contributions to Quality of Life Research (1996), the Secretary of State's Prize for Excellence in Interdisciplinary Research in Canadian Studies (1984) for his five-volume treatise North American Social Report: A Comparative Study of the Quality of Life in Canada and the USA from 1964 to 1974.

My eight favorites of Alex's many accomplishments are but a few select ones from a very long list. As a pioneer, at least in my TV image of one, Alex continues to ride high in the saddle. 